
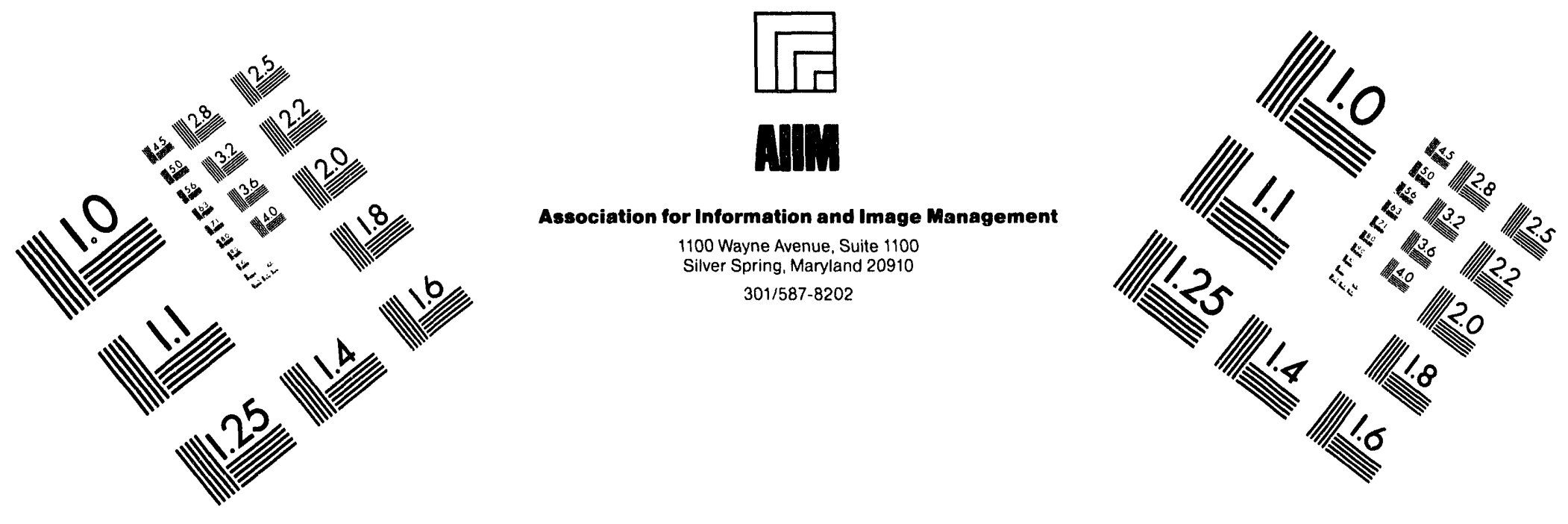

\title{
Centimeter
}

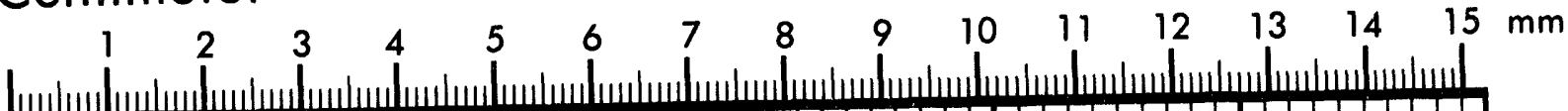
|ш⿻ Inches
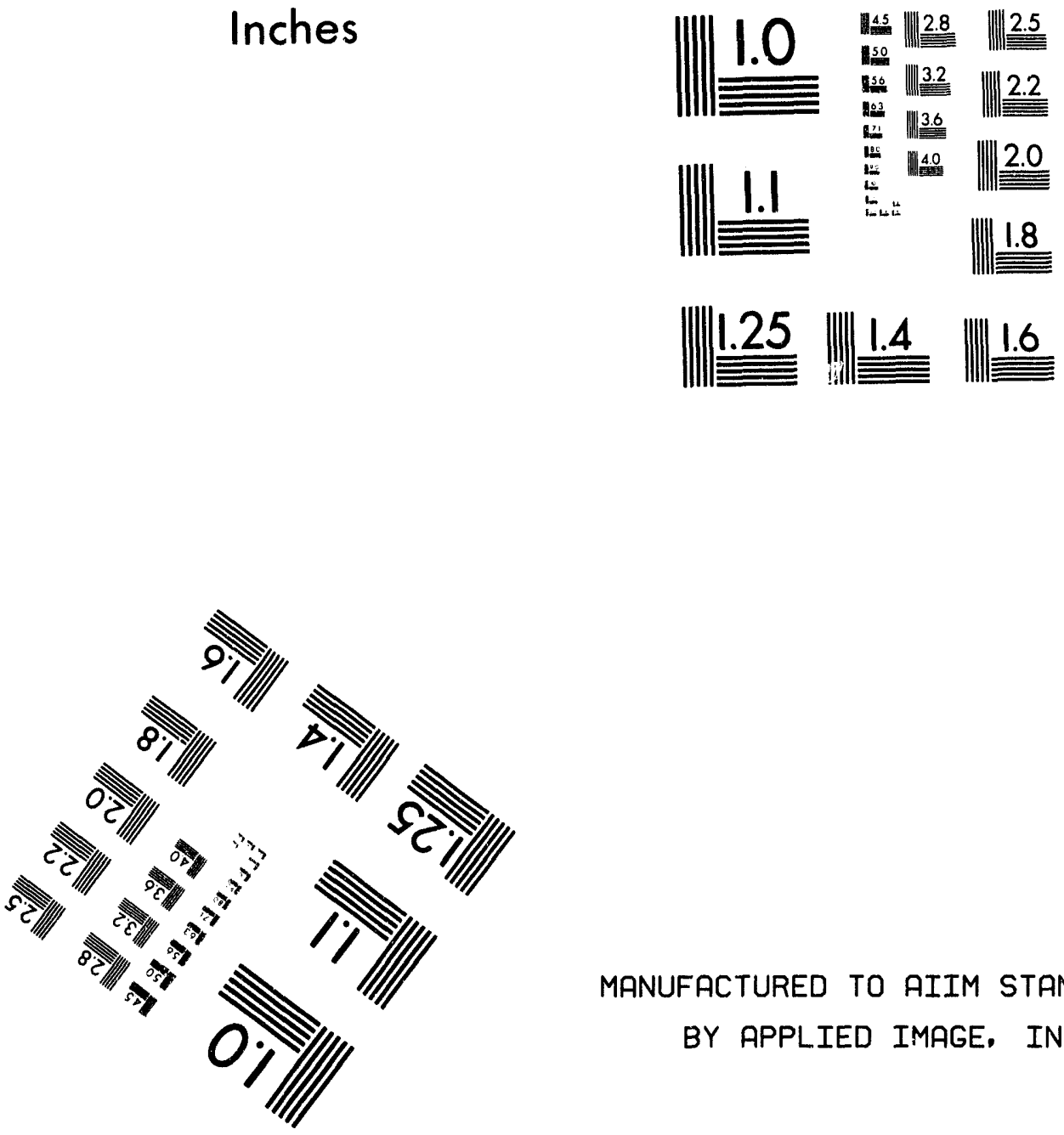

MANUFACTURED TO AIIM STANDARDS

$$
\text { BY APPLIED IMAGE, INC. }
$$

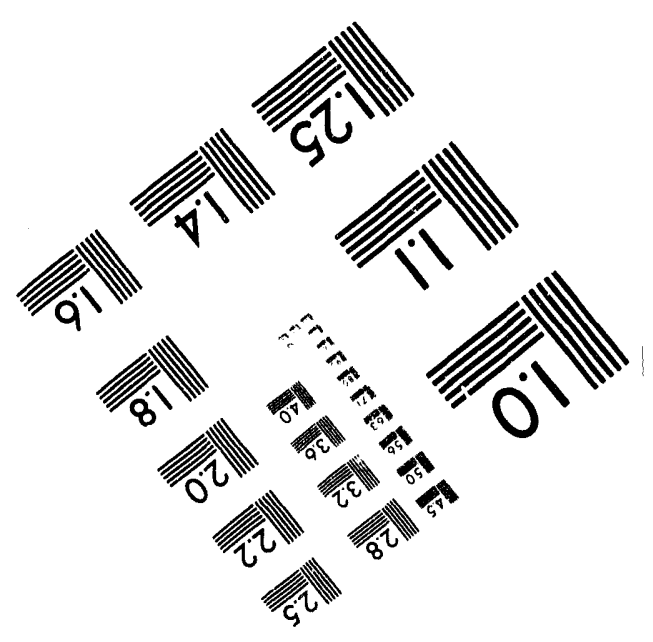



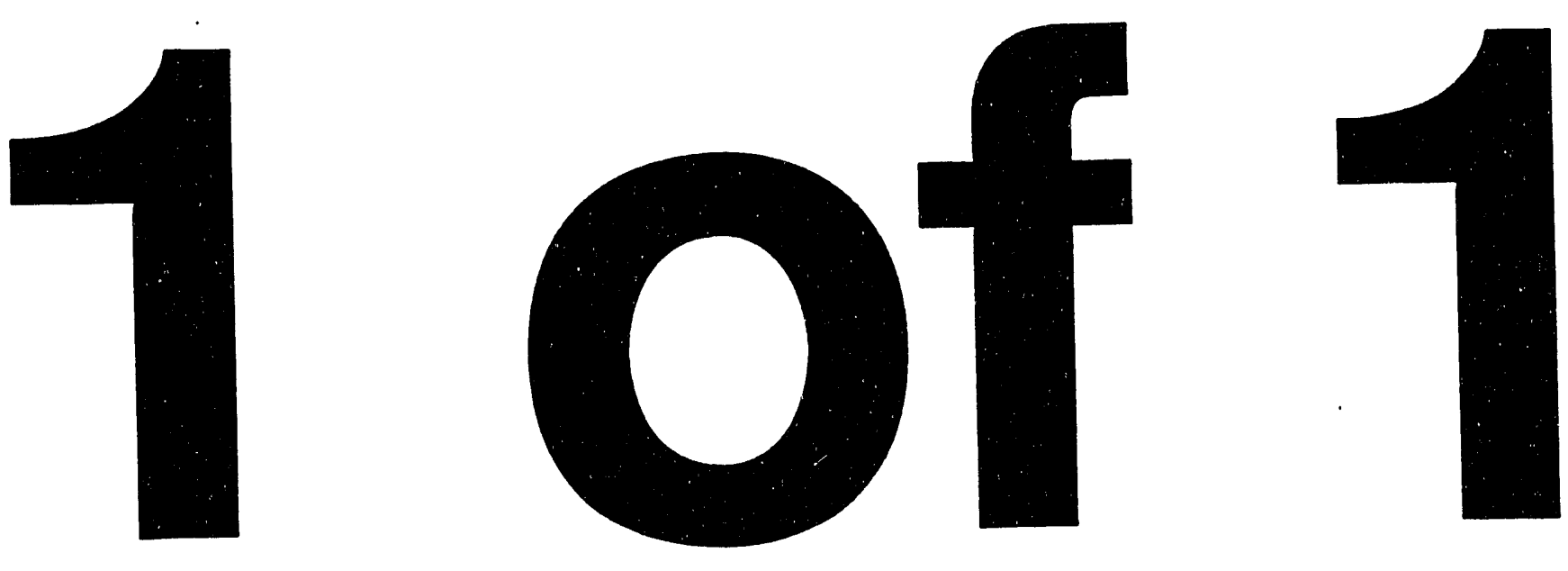
NUREG-1416

\section{Operational Experience and Maintenance Programs of Transamerica Delaval, Inc., Diesel Generators}

Manuscript Completed: April 1994

Date Published: May 1994

J. R. Rajan

Division of Engineering

Office of Nuclear Reactor Regulation

U.S. Nuclear Regulatory Commission

Washington, DC 20555-0001

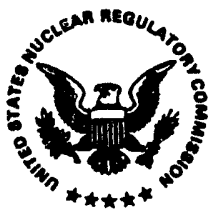

\section{MASTER}




\section{ABSTRACT}

Concerns regarding the reliability of 1 arge-bore, medium-speed diesel generators manufactured by Transamerica Delaval, Inc. (TDI) for application at domestic nuclear plants were first prompted by a crankshaft failure at Shoreham Nuclear Power Station in August 1983. A number of diesel generator components were identified which had potential deficiencies from a manufacturing and operational standpoint.

In response to these problems, 11 (now 8) U.S. nuclear utility owners formed a TDI Diesel Generator Owners' Group (Owners' Group) to address operational and regulatory issues relative to diesel generator sets used for standby emergency power. The Owners' Group performed extensive design reviews of all key engine components and developed recommendations to be implemented by the individual owners concerning needed component replacements and modifications, component inspections to validate the "as-manufactured" and "as-assembled" quality of key engine components, engine testing, and an enhanced maintenance and surveillance program.

The staff evaluation of the Owners' Group program is documented in NUREG-1216. The staff concluded that implementation of the Owners' Group recommendations, with minor modifications, established the adequacy of the TDI diesel generators for nuclear standby service as required by General Design Criterion 17 of Appendix A to 10 CFR Part 50. The staff further concluded that these actions ensured that the design and manufacturing quality of the TDI engines is within the range normally assumed for diesel engines designed and manufactured in accordance with 10 CFR Part 50, Appendix B. Continued reliability and operability of the TDI engines for the life of the facilities was ensured by implementation of the maintenance/surveillance program described in NUREG-1216. The most critical periodic maintenance/surveillance actions for key components were incorporated as license conditions.

Since 1985, substantial operational data and inspection results have been accumulated by the TDI Owners' Group on the TDI engines. Although a few problems have been found, the engine components have generally performed satisfactorily and the reliability of the machines has been on an upward trend. In addition, many of the surveillance procedures that are in place have proved to be as effective as inspections for identifying potential problems.

On the basis of operational experience and inspection results, the owners' Group provided information in its submittals of November 1992 and December 1993 to demonstrate that the special concerns of NUREG-1216 are no longer warranted. The Owners' Group contends that the TDI emergency diesel generators (EDGs) should be treated on a par with other EDGs within the nuclear industry and subjected to the same standard regulations, without the special requirements of NUREG-1216. In addition, the Owners' Group asserts that this action will improve availability of the engines for service, especially during outages, while maintaining current reliability levels. 
The NRC staff, with assistance from its consultants at Pacific Northwest Laboratories (PNL), has completed a review of the operational experience and inspection results contaired in the Owners' Group's submittals relative to the individual components. In addition, independent opinions were obtained from three leading diesel engine experts regarding these inspection requirements.

On the basis of its review, the staff's overall conclusion is that there is adequate and defendable justification for removing the present componentbased licensing conditions imposed on licensees based on recommendations in NUREG-1216 and that these TDI diesel engines can now be treated in the same regulatory manner as other EDGs within the nuclear industry. 
TABLE OF CONTENTS

ABSTRACT $: \ldots \ldots \ldots \ldots \ldots \ldots$

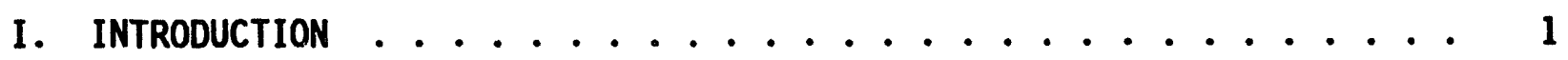

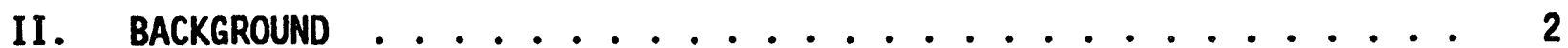

PHASE I PROGRAM (3); PHASE II PROGRAM (4);

MAINTENANCE/SURVEILLANCE PROGRAM (4)

III. DISCUSSION .................... 5

INSPECTION RESULTS (6); RECOMMENDATIONS OF THE EDG EXPERTS (8)

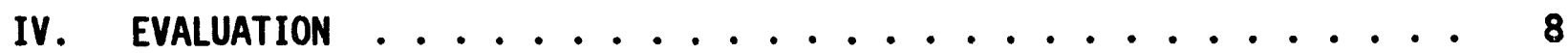

v. OVERALL CONCLUSIONS .................. 10

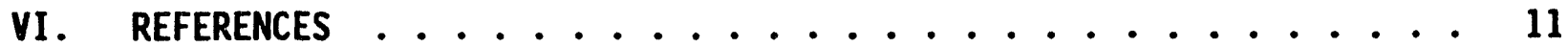
APPENDIX A

SUMMARY OF OPERATIONAL EXPERIENCE AND INSPECTION RESULTS

OF EMERGENCY DIESEL GENERATOR (EDG) COMPONENTS . . . . A-1

APPENDIX B

SUMMARY OF RECOMMENDATIONS BY THREE DIESEL GENERATOR EXPERTS . . B-1 APPENDIX C

IMPORTANT FEATURES OF A DIESEL GENERATOR PREVENTIVE MAINTENANCE PROGRAM C-1 APPENDIX D

SAMPLE LICENSE CONDITIONS

APPENDIX E

COMPONENTS REQUIRING ENGINE LOAD LIMITS AND/OR SPECIAL ROUTINE

MAINTENANCE AND SURVEILLANCE ......... E-1 


\section{INTRODUCTION}

During the 1970s, many utilities ordered diesel generators from Transamerica Delaval, Inc. (TOI) for installation at nuclear plants in the United States. The first of these engines to become operational in nuclear service were those at San Onofre Unit 1 in 1977. However, nuclear plant operating experience with TDI emergency diesel generators (EDGS) remained very limited until preoperational test programs were started at Shoreham and Grand GuIf Unit 1 in the early 1980s.

Concerns about the reliability of large-bore, medium-speed diesel generators manufactured by TDI for application at domestic nuclear plants were first prompted by a crankshaft failure at Shoreham in August 1983. However, a broad pattern of deficiencies in critical engine components subsequently became evident at Shoreham and at other nuclear and non-nuclear facilities employing TDI diesel generators. These deficiencies stemmed from inadequacies in design, manufacture, and quality assurance/quality control by TDI.

In response to these problems, 11 (now 8) U.S. nuclear utility owners' formed a TDI Diesel Generator Owners' Group to address operational and regulatory issues relative to diesel generator sets used for standby emergency power. On March 2, 1984, the Owners' Group submitted a proposed program ("TDI Owners' Group Program Plan") to the NRC that was intended to provide an indepth assessment of the adequacy of the respective utilities' TDI engines to perform their safety-related function through a combination of design reviews, quality revalidations, engine tests, and component inspections.

The Owners' Group program addressed three major elements concerning the manufacture, inspection, and operation of TDI diesel engines:

(1) Phase I: Resolution of known generic engine component problems to serve as a basis for licensing plants during the period before completion of Phase II of the Owners' Group program.

(2) Phase II: A Design Review/Quality Revalidation (DR/QR), of a large set of important engine components to ensure that their design and manufacture, including specifications, quality control and quality assurance, and operational surveillance and maintenance, are adequate.

(3) Expanded engine tests and inspections as needed to support Phase I and II programs.

The NRC staff concluded in NUREG-1216, a safety evaluation report (SER) of August 1986 (Reference 1) that the Owners' Group program incorporated the essential elements needed to resolve the outstanding concerns relating to the reliability of the TDI EDGs for nuclear service. In keeping with recommendations from consultants at Pacific Northwest Laboratories (PNL) that certain

1 Carolina Power and Light Co. (Shearon Harris), Cleveland Electric Illuminating Co. (Perry), Duke Power Co. (Catawba), Georgia Power Co. (Vogtle), Gulf States Utilities (River Bend), Entergy Operations, Inc. (Grand Gulf Units 1 \& 2), TVA (Bellefonte), Texas Utilities (Comanche Peak). 
components warrant special emphasis in terms of maintenance/surveillance (M/S) actions to ensure their adequate service, the staff incorporated key $\mathrm{M} / \mathrm{S}$ actions for these components as license conditions.

The TDI Owners' Group submitted a proposal in December 1992 (Reference 2) along with supplementary information on December 7, 1993 (Reference 3) recommending removal of the licensing conditions imposed in 1986 as part of a technical resolution to address the so-called TDI diesel generator issues identified in NUREG-1216.

Since 1985, more than 9000 hours of operation have been logged collectively by the TDI engines. Although a few problems have been found, the engine components have generally performed satisfactorily, and the reliability of the machines has been on an upward trend. In addition, many of the surveillance procedures that are in place have proved to be as effective as inspections for identifying potential problems.

On the basis of operational experience and inspection results the owners' Group has provided information in its submittal reports (References 2 and 3 ) to demonstrate that the special concerns of NUREG-1216 are no longer warranted. The Owners' Group contends that the TDI EDGs should be treated on a par with other EDGs within the nuclear industry and subjected to the same standard regulations, without the special requirements of NUREG-1216. In addition, the Owners' Group asserts that this action will improve availability of the engines for service, especially during outage:s, while maintaining current reliability levels.

The NRC staff, with assistance from its consultants at Pacific Northwest Laboratories (PNL) has completed a review of the operational experience and inspection results contained in the Owners' Group submittal reports relative to the individual components. In addition, independent assessments were obtained from three leading diesel engine experts regarding these inspection requirements.

On the basis of this review, the staff's overall conclusion is that there is adequate and defendable justification for removing the present componentbased licensing conditions, and that the criteria and methodology proposed by the Owners' Group may be used to review all TDI components with inspection or safety concerns.

The staff developed criteria for judging the advisability of changing the regulatory basis for the TOI engines. All criteria were fulfilled as discussed in Section IV of this safety evaluation.

\section{BACKGROUND}

The three major elements of the technical resolution to address the TDI EDG issues as discussed in the SER dated August 1986 (NUREG-1216), are summarized below. 


\section{PHASE I PROGRAM}

Phase I of the Owners' Group program focused on identifying and resolving significant engine component problems that had potential generic implications. Through an extensive review of TDI and other engine performance data in both nuclear and non-nuclear applications, the Owners' Group identified 16 components with such problems. These were:

- air start valve capscrews

- connecting rods

- connecting rod bearings

- crankshafts

- cylinder blocks

- cylinder heads

- cylinder head studs

- cylinder liners
- engine base and bearing caps

- engine-mounted electrical cables

- high-pressure fuel injection tubing

- jacket water pumps

- piston skirts

- push rods

- rocker arm capscrews

- turbochargers

The Owners' Group recommended that problems with these component,s be resolved before the TDI engines were placed into service to support full-power nuclear plant operations. To resolve the problems with these components, the Owners' Group contracted with Failure Analysis Associates (FaAA), Palo Aito, California, and Stone and Webster Engineering Corporation (SWEC), Boston, Massachusetts, to perform extensive design reviews. Each component was addressed by these consultants in one or more design review documents. Each design review report included, as appropriate, materials evaluations, 10ad and stress analyses, fracture and fatigue analyses, and evaluations of required maintenance and surveillance. On the basis of these reviews, the Owners' Group arrived at conclusions regarding the basic adequacy of the 16 components with known problems, and recommended actions that should be taken by the engine owners.

Pacific Northwest Laboratories (PNL) was contracted by the NRC to assess the Owners' Group findings. PNL's assessment of the findings stemming from the Phase I program is documented in detail in PNL-5600 (Reference 4). On the basis of its assessment, PNL concluded that the Owners' Group had established a technical basis for the licensees to qualify all of the components with known problems (i.e., Phase I components) for nuclear service. PNL generally endorsed all of the Owners' Group recommendations pertaining to modifications, inspections, and maintenance/surveillance of Phase I components. However, PNL recommended some additional actions in these areas beyond those the Owners' Group had recommended. In addition, PNL and the staff concluded that five of the components warrant special emphasis in terms of needed load restrictions and/or maintenance/surveillance to ensure satisfactory service of these components.

In Revision 2 of the DR/QR report, the Owners' Group (Reference 5) proposed, and the staff accepted, that a complete engine overhaul be performed at approximately 10-year intervals. Namely, the DR/QR report specified that one engine/unit be disassembled and inspected at the refueling outage occurring before the 10-year interval and the second engine at the refueling outage occurring after the 10-year interval. For plants with three engines, the third engine would be disassembled and inspected during the second refueling 
outage after the 10-year interval. In addition, the Owners' Group later proposed that a one-time inspection be performed at about five years. The one-time 5-year inspection generally involved the same components as the 10year overhaul inspection; however, only a sample of some types of components (typically 25\%) were inspected.

\section{PHASE II PROGRAM}

Phase II of the Owners' Group program proceeded beyond known problem areas to systematically consider all components (approximately 150 to 170 component types per engine) important to the operability and reliability of the engines. Phase II was intended primarily to ensure that significant new problem areas do not develop in the future because of deficiencies in design or quality of manufacture. The Owners' Group performed the Phase II design reviews and, as was the case for Phase I, recommended needed component upgrades and modifications and component inspections to validate quality of manufacture and/or assembly. A major element of the Phase II program was the preparation of a comprehensive engine maintenance/surveillance $(M / S)$ program to be implemented by the individual owners.

Design reviews performed by the Owners' Group for engine components at one plant were generally applicable to similar components at other plants. Similarly, quality revalidation inspections recommended by the Owners' Group for engine components at one plant were generally applicable to similar engine components at other plants, although the actual inspections were generally performed by the individual owners. The DR/QR reports for the Shoreham DSR-48 engines and Comanche Peak DSRV-16-4 engines generally constituted the leadengine reviews. The reports were extensively referenced in DR/QR reports prepared for other plants.

The staff's contractor, PNL, performed a detailed audit review of the DR/QR reports for the Shoreham DSR-48 engines and for the Comanche Peak DSRV-16-4 engines. These PNL reviews are documented in PNL Reports PNL-5336 (Reference 6) and PNL-5444 (Reference 7), respectively. PNL found that the DR/QR efforts fully met the intent of the Owners' Group program plan, which was to establish "reasonable assurance of the ability of the TDI engines to provide reliable backup power supplies for nuclear power plant service."

The staff concluded in its SER dated August 1986, (Reference 1) that implementation of the Owners' Group recommendations in the Phase II reports will be effective in improving and ensuring the design adequacy and quality of the engine components and, hence, the reliability and operability of the TDI engines at the various Owners' Group nuclear plants.

\section{MAINTENANCE/SURVEILLANCE PROGRAM}

The staff viewed the implementation of a comprehensive $\mathrm{M} / \mathrm{S} \mathrm{plan}$ to be a key element of the overall effort to establish and maintain TDI diesel engine reliability and operability.

As a result of its generic Phase I and Phase II component reviews, the Owners' Group developed an $M / S$ plan applicable to each member utility's engines. The 
plan for each plant, which supplemented the existing TDI Instruction Manual, was developed by the Owmers' Group from (1) its detailed review of each component's service history; (2) TDI Service Information Memoranda (SIMs) and correspondence on specific components, and (3) the Owners' Group technical reviews done during the Phase II DR/QR reviews. The Owners' Group recommendations are documented in Appendix II of the DR/QR report for each plant.

The staff concluded in NUREG-1216 that the following elements constituted an acceptable program:

(1) the recommendations concerning operation, testing, inspection, maintenance, adjustment, overhaul, and repair of the engine as incorporated in the TDI Instruction Manual, SIMs and TDI correspondence on specific $M / S$ issues

(2) the M/S recommendations developed by the Owners' Group in Appendix II, Revision 2, of the $D R / Q R$ reports

(3) additional items required by the staff in individual plant license conditions

The staff also specified in NUREG-1216 that each plant owner commit to an acceptable $\mathrm{M} / \mathrm{S}$ program, as identified above, before the staff issued final plant-specific SERs addressing the final resolution of the TDI engine issues.

Typically, detailed steps of preventive M/S programs for such important safety-related systems as diesel generators are not incorporated as part of the plant license or the plant technical specifications. Accordingly, changes to these programs are not normally subject to NRC staff review and approval. In keeping with the PNL recommendations as endorsed by the staff in NUREG1216, that certain components warrant special emphasis in terms of $M / S$ actions to ensure their adequate service, the staff included key $M / S$ actions for these components as licenses conditions.

\section{DISCUSSION}

In its submittal reports of November 30, 1992, and December 7, 1993 (References 2 and 3), the Owners' Group is proposing that the current prescriptive $\mathrm{M} / \mathrm{S}$ requirements, including a specified overhaul frequency, be removed as a license condition and the licensees be allowed to determine when an overhaul is required and how it will be conducted. The Owners' Group is presently developing a generic diesel management program in conjunction with the manufacturer which incorporates predictive maintenance techniques based on a combination of inspections, monitoring, and trending. The Owners' Group proposes to use this generic diesel management program in lieu of the current maintenance/surveillance requirements. 


\section{INSPECTION RESULTS}

On the basis of the substantial operational experience of the TDI EDGs accumulated since 1985 and the inspection results of the EDG components, the Owners' Group has provided information in its submittal reports of November 30, 1992, and December 7, 1993 (References 2 and 3) to demonstrate that the special concerns of NUREG-1216 are no longer warranted. The Owners' Group has recommended removing the license conditions related to EDG component inspections involving teardowns and surveillance requirements.

The Owners' Group has analyzed the need for engine overhauls in accordance with the current $D R / Q R$ requirements. Their analysis and conclusions are based on an understanding of the historical concerns for each component affected by the overhaul and the results of extensive inspections performed by the licensees who make up the TDI Owners' Group. The information in its submittal reports includes component description, component identification number per the DR/QR Appendix II, "Preventive Maintenance (PM) Task Description," the manufacturer's replacement/overhaul recommendations, the number of engine hours run between inspections or cumulative engine hours, number of engine starts, inspection findings, and the percentage of all components in service covered by the inspections. The results of the inspections compiled by the Owners' Group in its submittal reports (References 2 and 3 ) indicate that most teardowns have shown little or no wear on internal engine components.

However, with continuing operation, it is possible that problems could occur with specific components which could require inspection or overhaul of affected components. The Owners' Group is proposing that such actions be determined on a case-by-case basis, and that inspections or overhauls be performed so that engine reliability and availability are maximized. The Owners' Group contends that the primary purpose of EDG 10-year teardown inspections is to document the condition of the specific components, not to replace components, since most components being inspected show little or no wear. However, as a matter of good maintenance practice, these components are generally replaced after a teardown inspection, regardless of condition. These teardowns can result in reassembly errors or entry of foreign materials resulting in increased wear or decreased engine reliability.

The Owners' Group believes that an overhaul will be needed during the life of these engines as they are currently operated. However, due to the limited number of run hours and the availability of periods to perform major teardowns the licensees need the flexibility to determine when an overhaul is required and how an overhaul is conducted.

The Owners' Group contends that some of the early concerns with EDG components were caused by the deleterious effects of the fast starts and loading of EDGs in nuclear service. The Owners' Group notes that the life expectancy of most engine components in commercial service, which are not subject to fast starts, is far greater than the estimated life of EDG components in nuclear service based on early data.

Al1 licensees have the authority to delete fast-start and loading requirements on the basis of Generic Letter (GL) 84-15, and are committed to doing so. How ler, some licensees have not taken this step for a number of reasons. 
First, many engines have control systems which will not allow a slow start. The necessary changes in such control systems are currently being implemented. Second, some of the TDI licensees want to consolidate all changes for a particular technical specification (TS) to lessen the impact on the licensee and the NRC workload resulting from a TS change request. The staff is currently preparing a GL addressing the requirements for accelerated testing of emergency diesels. Most licensees are waiting for this GL to be issued before requesting a change to their TSs which would include a request for the deletion of the fast starts. Once the slow start option is implemented and accelerated testing is eliminated, engines at nuclear plants will be operated similarly to those in commercial service, and the expected iffe of components in engines at nuclear plants should compare favorably with commercial engine components. The data from engines in nuclear service which have implemented the slow-start option supports this contention. Since the manufacturer's recommendations for commercial operation of TDI/EDG components prior to overhaul indicate that there are substantial safety margins available, appropriate changes can be made in $M / S$ requirements based on realistic estimates or component life expectancy, and flexibility can be achieved in the frequency of performing teardown inspections.

The Owners' Group, in its submittal reports, has also discussed the need for flexibility in scheduling teardown inspections from the standpoint of shutdown risk management (SRM). According to the Owners' Group, the "available windows" of outage time of sufficient length to allow engine teardowns and/or overhauls are being shortened because of SRM requirements. The "available window" during which a diesel can be removed from service for inaintenance depends on a number of factors, including plant design, availability of alternate power sources, fuel handling schemes, and other operational, maintenance, or inspection requirements. These factors cause the "available window" to vary from outage to outage. Typically, the "available window" is between 10 and 21 days; however, SRM programs have compressed this "window" by as much as 20\%. As a result of this shortening of "available windows," all plants need maximum flexibility in scheduling EDG maintenance activities (i.e., schedule major diesel work during times when longer "windows" are available without impacting overall outage length). Time-directed teardowns/overhauls do not allow this flexibility. The Owners' Group is proposing a generic diesel management program which combines predictive maintenance, surveillance, and inspection. The Owners' Group contends that with this program, considerable flexibility can be achieved in the frequency of performing teardowns and/or overhauls without sacrificing engine reliability.

Typical components that are inspected or replaced or both during an engine overhaul are turbochargers, main bearing caps/studs, cylinder blocks, connecting rods/bearings/bushings, cylinder heads, push rods, lower cylinder liner seals, base assemblies, crank shafts, cylinder liners, pistons/rings, fuel injection tubing, and rocker arm capscrews/drive studs. Problems with these components resulting from the intrusive inspections could certainly limit or preclude the engine's acceptable power output. Disassembly of these components can result in the accidental introduction of dirt and other foreign materials that may harm the engine. In addition, these components are assembled with a precision fit of the mating surfaces. Disturbance of these 
fits can cause different wear patterns to develop, resulting in accelerated wear and a shortened component life.

The operational data and the inspection results for the key components are reviewed in Appendix A. The Owners' Group assesses that these components can be expected to operate for the 40-year life of the plant without failure. The Owners' Group diesel management program contains a comprehensive list of engine and auxiliary system parameters to be monitored and trended. This diesel management program offers guidance on the monitoring frequencies, normal operating ranges for the various parameters, alert levels, and corrective actions. The licensees will monitor and trend data collected during engine runs and standby conditions to determine the overall operational readiness of the engine. Should the monitored data indicate that a potential problem exists, additional tests and evaluations would be conducted which could result in teardown inspections or component replacement or both. It is the intent of the Owners' Group diesel management program to detect problems and correct them before they affect the ability of the engine to perform its design function.

\section{RECOMMENDATIONS OF THE EDG EXPERTS}

The staff solicited independent assessments from three EDG experts of the operational experience and inspection results contained in the Owners' Group submittals (References 2 and 3 ). The experts who participated in this review are Paul Louzecki, Adam Henriksen, and B. J. Kirkwood. Together, they represent well over 100 years of large diesel engine experience. They were of the opinion that there were no adverse trends in the data obtained from the inspection results, and that the Owners' Group submittals represented adequate understanding of inspection and maintenance needs. On this basis, they thought that consideration of realignment of the TDI engine regulatory requirements to those considered normal for such equipment was a positive action. The recommendations offered by the EDG experts and the staff's evaluation of specific recommendations is summarized in Appendix B of this report.

\section{EVALUATION}

The staff, with assistance from its consultants, developed specific criteria to guide the review process and evaluate the adequacy of the rationale for the removal of component-based license conditions. The criteria consisted of the following five elements:

- Adequate justification should exist for changing applicable license conditions for the TDI engines.

- $\quad$ Since the original regulatory issue was improvement of TDI engine reliability, the current TDI engine reliability should be equal to or better than the industry average.

- Because specific surveillances/inspections were imposed by regulation to ensure that acceptable engine conditions were being maintained, the inspection results should not identify unacceptable findings. 
The Owners' Group should have an alternative diesel management program with elements that are judged by the regulatory staff to be reasonably and equally effective compared to current license requirements in maintaining diesel reliability.

- The underlying source or technical basis for the proposed regulatory change should be justified by authoricies and expertise equal to that which determined the current regulatory requirements.

As discussed in the following paragraphs, all five criteria have been satisfied. The current TDI engine reliability was found to be equal to or better than the industry average. In the period between January 1990 and December 1992, the median reliability of TDI diesels was found to be 0.9906 . This is about $1 \%$ better than the nuclear industry average, and well above NRC's highest goal of 0.975 .

Specific surveillances/inspections were imposed by NRC regulations to ensure that acceptable TDI engine conditions were being maintained. A review of the operational database and the inspection results for the key components, as discussed in Appendix $A$, show no unacceptable findings. In fact, most inspections did not uncover any signs of wear or degradation that need to be addressed.

NRC-sponsored research (Reference 8 ) has indicated the potentially negative consequences of intrusive inspections on components and engine reliability as a result of current practices. In a study of failures related to aging, a failure curve, sometimes called the "bathtub" curve, correlates the change in failure rate witk age. The beginning segment of the curve represents a "wearin" portion, with a higher failure rate associated with many pieces of new equipment. Once the machinery is broken in, the failure rate is at its lowest and remains constant for a period of time. As the machinery wears and reaches the end of its lifetime, the failure rate increases. The challenge is to determine the time scale for these regions for each piece of equipment. On the basis of these studies, it is generally believed that the diesel engine's reliability is considerably lower during the "wear-in" period, and some engines may be on the lower end of the acceptable range of reliability, during the "wear-in" period of operation.

Some of the early concerns with EDG components were due to the deleterious effects of fast start and loading of EDGs in nuclear service. Component life expectancy in commercial TDI engines which are not subject to fast starts is far greater than life expectancy ior TDI engine components in nuclear service. Although the fast-start requirements have been relaxed on the basis of GL 8415, not all licensees have implemented the changes in the EDG control system to permit slow starts. All members of the Owners" Group are committed to implementing these changes in the near future. The staff is also addressing the issues related to accelerated testing in a generic letter to be issued shortly. Once the slow start option has been implemented and accelerated testing has been eliminated, nuclear service engine operation will more closely match that of engines in commercial service and the expected component life for TDI engines in nuclear service should compare favorably with commercial engine component life. The data from engines in nuclear service 
which have implemented the slow-start option supports this contention. A review of the manufacturer's recommendations for commercial operation of TDI/EDG components before overhaul indicates that there are substantial safety margins available for most components in nuclear service. The staff concurs with the Owners' Group recommendation that by combining predictive maintenance, surveillance, and inspections, as in the proposed generic diesel management program, considerable flexibility can be achieved in the frequency of performing engine teardowns and/or overhauls without sacrificing engine reliability.

The Owners' Group contends that the "available windows" of outage time of sufficient length to allow engine teardowns and/or overhauls are being shortened due to SRM requirements. As a result of this shortening of available windows, all plants need maximum flexibility in scheduling EDG maintenance activities. The adoption of a predictive maintenance program for EDGs as proposed, in lieu of the current time-directed teardown/overhaul requirements would give the licensee this flexibility without jeopardizing engine reliability.

The Owners' Group has requested the removal of inspection requirements from the license conditions. The Owners' Group proposes to continue appropriate inspections; however, scope, inspection schedules, and especially the amount of intrusive inspections involving disassembly would be changed to maximize EDG availability and reliability. Inspections would be planned to respond to monitoring and trending results and where other maintenance activities make the component accessible, such as in response to failures of nearby components or where monitoring is indicating an end of component life conditions. The Owners' Group will continue appropriate inspections, especially those not involving engine disassembly. Inspections will be defined and included as part of a well-managed engine program currently under preparation. Elements of correct engine management have been reported previously to the NRC and industry (References 8 and 9). Key features of an EDG management program, acceptable to the staff (see Appendix C of this safety evaluation) have been discussed and provided to the Owners' Group. The Owners' Group agrees that each member would adopt the group's proposed generic management program, resolution, or mitigating actions, and that ail actions are intended to be acceptable to the manufacturer.

Finally, the underlying source or technical basis for the proposed regulatory change is equal in expertise to that which was responsible for recommending the current regulatory requirements. The TDI Owners' Group, with support from the manufacturer, was instrumental in preparing the technical basis for the original regulatory conditions in NUREG-1216.

\section{OVERALL CONCLUSIONS}

The staff, with assistance from its consultants and recognized diesel engine experts, concluded that the regulatory requirements on TDI engines may be reconsidered at this time. This conclusion is based on a review of the current reliability data of the TDI engines, the Owners' Group inspections of the last several years, and the opinion of experts who have experience in the design and operation of large diesel engines. The staff believes that the TDI 
Owners' Group, like any other owners group, must address the unique maintenance needs for its specific engine to keep the reliability factor acceptable. With a current median reliability of 0.9906 , the TDI Owners' Group, and its individual owners, seem to fully understand the maintenance needs of this engine. The staff further believes that there is sufficient information in the Owners' Group submittal reports to conclude that TDI engine operation at authorized loads is acceptable under normal NRC regulatory oversight procedures for EDGs. The staff and its consultants, in their review of the TDI submittal reports and the operational database, did not uncover any new concerns or issues. Individual reports from recognized experts endorse many of the TDI engine management practices, inspections, or precautions. The Owners' Group intends to incorporate most of the inspections and precautions from che current $M / S$ requirements in its generic diese1 management program and appropriately supplement these inspections with alternate condition monitoring procedures. All members of the Owners' Group are committed to implement this diesel management program.

The key features of a maintenance program which the staff finds acceptable are delineated in Appendix $C$ of this safety evaluation. The staff has reviewed the preliminary version of the diesel management program, which the Owners' Group is proposing in lieu of the current $M / S$ requirements. The staff finds the principal elements of this program acceptable. The proposed maintenance program is in conformance with the requirements in Regulatory Guide 1.160, "Monitoring the Effectiveness of Maintenance at Nuclear Power Plants," dated June 1993, which endorses NUMARC 93-01 dated May 1993, "Industry Guide for Monitoring the Effectiveness of Maintenance at Nuclear Power Plants."

Accordingly, the staff has concluded that the license conditions related to the periodic M/S program (see Appendix D of this safety evaluation) for certain components (see Appendix $E$ of this safety evaluation) which were imposed on the licensees based on the recommendations in NUREG-1216, be removed at this time. Therefore, the detailed steps of the preventive $\mathrm{M} / \mathrm{S}$ programs will not be subject to NRC staff review and approval. However, the staff believes that future revisions of the $M / S$ program would be subject to the provisions of 10 CFR 50.59 (Code of Federal Regulations) in view of the importance of the $M / S$ program in ensuring the operability and reliability of the engines. The staff will require that the owners of each plant commit to the current $M / S$ program in the interim period preceding the implementation of the generic diesel management program currently under development in association and agreement with the manufacturer. The transition from the current $M / S$ program to the generic diesel management program could be accomplished under the provisions of 10 CFR 50.59. The TS requirements of subjecting the diesel to an inspection in accordance with procedures prepared in conjunction with its manufacturer's recommendations for the class of standby service would continue to remain in effect, similar to the TS requirements on other EDG manufacturers.

VI. REFERENCES

(1) NUREG-1216, "Safety Evaluation Report Related to the Operability and Reliability of Emergency Diesel Generators Manufactured by Transamerica Delaval, Inc.," dated August 1986. 
(2) TDI Owners' Group submittal proposing removal of licensing conditions imposed by NUREG-1216, dated November 30, 1993.

(3) TDI Owners' Group Generic Licensing Submittal No. 2 for Emergency Diesel Generator Conditions of License for Utilities with Enterprise Engines, dated December 7, 1993.

(4) PNL-5600, "Review of Resolution of Known Problems in Engine Components for Transamerica Delaval Inc. Emergency Diesel Generators," December 1985.

(5) George J. B., Chairman, TDI Owners' Group, letter to H. R. Denton, NRC, "Revision 2 of Final DR/QR Reports for TDI Diesel Generators," May 1, 1986.

(6) PNL-5336, "Review of Design Review and Quality Revalidation Report for the Transamerica Delaval Diesel Generators at Shoreham Nuclear Power Station Unit 1," October 1985.

(7) PNL-5444, "Review of Design Review and Quality Revalidation Report for the Transamerica Delaval Diesel Generators at Comanche Peak Steam Electric Station Unit 1," October 1985.

(8) NUREG/CR-5057, K. R. Hoopingarner and F. R. Zaloudek, "Aging Mitigation and Improved Programs for Nuclear Service Diesel Generators," Pacific Northwest Laboratory, PNL-6397, December 1989.

(9) NUREG/CR-5078, E. V. Lofgren, W. Henderson, D. Burghardt, L. Kripps, B. Rothleder, "A Reliability Program for Emergency Diesel Generators at Nuclear Power Plants," Science Applications International Corporation, December 1988. 


\section{APPENDIX A \\ SUMMARY OF OPERATIONAL EXPERIENCE AND INSPECTION RESULTS \\ OF EMERGENCY DIESEL GENERATOR (EDG) COMPONENTS}

The operational data and inspection results of key EDG components compiled by the TDI Owners' Group are summarized below.

\section{Base Assemblies}

In the original TDI Owners' Group review of the DR/QR report, it was determined that adequate factors of safety exist in the design of this component. Problems with this component were reported in non-nuclear service engines and were the result of inadequate bolt preload and; in one case, marginal strength due to an inferior quality casting. Subsequent testing and/or inspections have been made by the owners to confirm that castings in service are of acceptable quality. In addition, steps have been taken to ensure adequate bolt preload.

The Owners' Group submittal reports cited 52 inspections representing $90 \%$ of the total population of base assemblies. The total (average) hours logged in EDG operation is 900 and the average number of starts is 400 . No problems were noted from the inspections.

These inspection results, coupled with previous Owners' Group analyses, show that the base has a life expectancy of more than 40 years. The staff, and its consultant at PNL, concluded in Reference 4, Section 4.12.3.2.1, that the components of the base assembiy have sufficient strength to operate at full load, provided the base casting and bolting components meet their nominal material and dimensional specifications, and the bolt torque specifications are maintained. As noted above, sufficient inspections/tests have been completed to indicate that the casting and bolt specifications are adequate. On this basis, the Owners' Group concludes that el iminating time-based inspections of this component is appropriate. Similar experience with nonnuclear engines shows a life expectancy in excess of 40 years. The Owners' Group diesel management program will have provisions for monitoring the condition of the base assembly. Visual inspections during normal operation, as well as during startups and warmups, would indicate if the base assembly is properly anchored and torqued. In addition, a change in the vibration measurements would indicate potential problems with this component.

\section{Main Bearing Caps/Studs}

Concerns about the main bearing caps/studs were initially raised by the cracks observed in the bearing cap stud holes at the Shoreham plant in 1984. The cause of this problem was related to the stud removal method (Reference 4, Section 4.12.3.2.1). After corrective actions were implemented, cracks have not been observed in subsequent inspections.

The Owners' Group submittal reports cited 108 inspections of caps, studs, and nuts, which is $50 \%$ of the components currently in service. The total (average) hours logged in EDG operation is 1,000 and the average number of 
starts is 490. All inspections were conducted with at least 600 hours of operation. A number of inspections have been performed on engines with more than 2,000 hours of operation. No problems were noted during these inspections. On the basis of the high safety factors and favorable inspection results, the Owners' Group concluded that these components should not require overhaul for the 40-year Iife of the plant. Manufacturer information indicates that this component in non-nuclear engines has a life expectancy in excess of 40 years.

Early indication of main bearing caps/stud problems will be obtained by monitoring several parameters which include hot and cold crankshaft web deflections and amount of wear particles in engine $0 i 1$.

\section{DSR-48 Series Engines--Crankshafts}

The only utility with the DSR-48 engine is the River Bend station. The EDG engines at River Bend have crankshafts with the same dimensions as the replacement shafts at Shoreham. However, because of differences in the generators and flywheels between the two installations, resulting crankshaft torsional stresses are different. A complete analysis of the Shoreham replacement crankshaft has shown that it has a fatigue 11 fe in excess of 40 years under nuclear service operating conditions. Comparison of the crankshaft torsional stresses in the Shoreham engines at an operational load of $3300 \mathrm{~kW}$ to the torsional stresses in the River Bend engines at an operational load of $3130 \mathrm{~kW}$ shows that the torsional stresses are equivalent at these respective loads. Therefore, the River Bend engines have been derated for nuclear service. The Owners' Group and PNL analyses indicate a projected fatigue 1 ife in excess of 40 years for the River Bend crankshafts at loads under $3130 \mathrm{kH}$ (Reference 4, Section 4.6.7.2).

A significant number of fillets, oil holes and journals have been inspected on the DSR engines. The inspections were conducted with over 700 hours in EDG operation and 270 starts with no problems. The River Bend engines have been derated and are operated at less than $3130 \mathrm{kH}$ at all times. On the basis of previous analyses conducted by the Owners' Group and PNL (Reference 4, Section 4.6.7.2), engine operational power limits and the inspection results, the Owners' Group believes that overhaul of the River Bend crankshafts should not be required for the 40-year life of the engine. Manufacturer information on non-nuclear engines indicate a life expectancy in excess of 40 years for the crankshaft.

The Owners' Group diesel management program will have provisions for monitoring several parameters which would give an early indication of potential problems and the need to perform teardown inspections. These parameters include hot and cold crankshaft web deflections, amount of wear particles in engine oil and vibration amplitudes.

\section{DSRV-16 Crankshaft}

The DSRV-16 crankshafts at each site have been independently evaluated to determine the impact of torsional stresses on the life of the component. No problems have been identified with this component. The Owners' Group analyses 
(Reference 4, Section 4.7) indicates a fatigue life in excess of 40 years for these components.

Approximately $25 \%$ of the oil holes, fillets and journals have been inspected on the DSRV-16 crankshafts. The minimum number of hours of engine operation at inspection was more than 700 , while several inspections were done on engines with more than 2,000 hours of operation. More than $70 \%$ of the engines are already operating in a region of the fatigue curve, where imposition of additional stress cycles is no longer a concern. Based on operating power limits, calculated fatigue life in excess of 40 years, and the positive inspections conducted with significant operating hours, the Owner Group concludes that this component would not be expected to require an overhaul within the 40-year operating life of the engine.

As stated earlier, the Owner Group diesel management program will require monitoring and trending of several parameters which would give an early warning and need for a teardown inspection of this component.

\section{Cylinder Blocks}

A thorough design review of this component was completed during the initial $D R / Q R$ review. This review indicated that some castings fabricated during the period when the Owners' Group engines were manufactured could contain

Widmanstaetten graphite. Widmanstaetten graphite is an inclusion that weakens the grey iron casting. It was shown that blocks containing this material have a greater potential for developing cracks. However, it was also shown that should these cracks develop for any reason, they would not affect the block's ability to perform its intended design function. Analyses indicated that cracks would tend to arrest without impacting the block performance. However, if the worst case scenario of crack propagation is assumed, it was shown that the water flow would be to the block exterior. This degradation would not impact engine performance and would be readily detectable. A cumulative fatigue usage index formula was developed and an inspection frequency was established based on that usage factor. The Owners' Group and PNL concluded in the earlier reviews that "If cumulative results of these inspections over several powe: plant fuel cycles show that one or more of the inspections reveal nothing of significance, the scope and frequency of the inspections could be reconsidered" (Reference 4, Section 4.9.5.2).

All engines currently in nuclear service have had block top inspections performed with 600 hours or more of EDG operation. No block cracking has been identified. On the basis of design analyses of engine blocks which indicate that cracking will not impact EDG performance and inspection results of engines with significant accumulated operating hours, the Owners' Group expects that this component will operate for the life of the plant without overhaul. Non-nuclear experience with this component indicates a life expectancy in excess of 40 years. The Owners' Group diesel management program has provisions to monitor potential crack growth via nonintrusive techniques, such as tracking the frequency of jacket water and lube oil makeups, and looking for signs of contaminants in lube oil and jacket water. 


\section{DSRV-16 Articulated Connecting Rods}

Problems have been found on DSRV articulated connecting rods with 1-1/2-in. bolts. These problems were discovered before the DSRV engines were used in nuclear service and during the early startup periods of the nuclear engines. The root cause of these problems was determined to be inadequate connecting rod bolt preload. To address this concern, the Owners' Group utilize assembly procedures which accurately verify connecting rod preload (stretch or torque measurement techniques). These preload measurement methodologies have been in use during past inspections. Since the implementation of these methodologies, no connecting rod problems have been reported.

TDI engines at one plant are furnished with 1-7/8-in. bolts in the connecting rods. Analyses indicate that bolt stresses are satisfactory as long as the bolts are properly torqued and the engine operating load is limited so that connecting rod stresses remain below the fatigue initiation curve. Operating load for this engine has been limited to ensure that this condition is met. Preload measurement is also used to ensure proper bolt loading. There are 144 pairs of articulated connecting rods in service in 18 engines.

Extensive inspections of the connecting rods have been conducted without uncovering any problems. Several engines had logged more than 2,000 hours of EDG operation at the time of the inspections. Ali 1icensees have implemented the use of preload measurement techniques. For the $1-1 / 2-i n$. bolts, adequate margin against fallure has been shown to exist at engine design load. The one utility with engines using the 1-7/8-in. bolts has instituted engine operating load limits to ensure that fatigue fallure is precluded. On the basis of the design margins, the use of preload measurements, an operating load 1 imit for engines with 1-7/8-in. bolts and the inspection results, the Owners' Group expects this component to last in excess of 40 years without overhaul. However, the Owners' Group will verify preload whenever a connecting rod assembly is replaced or overhauled.

Non-nuclear users typically run engines 50,000 hours before replacing of this component and 35,000 hours before replacing the rod eye bushing. The Owners' Group diesel management program will have provisions to monitor this component through several means. 011 analysis will be performed to detect the presence of wear metals indicating abnormal bearing/bushing wear. Engine analyzers would be utilized to gain information about abnormal functions of cylinder power components including connecting rods.

\section{Pistons/Rings}

All nuclear users have installed the AE model piston skirts. These piston skirts have previousiy been qualified at the rated engine load and have been validated for their fatigue iffe on 13 of the 20 engines in service. PNL concluded in an earlier analysis (Reference 4, Section 4.16.3) that the AE model piston skirts are adequate for service at their rated load and overload conditions. There are currently 304 pistons in service in 20 engines and 91 inspections have been performed. The average run time of EDGs preceding inspections is 800 hours and the average number of starts is 500 . The inspections revealed no problems. This represents $25 \%$ of the total population 
of pistons inspected. Pistons and rings have been one of the more reliable components in nuclear service. Some inspections have been conducted with more than 2,000 hours of operation. Inspections have revealed no stress- or wearrelated concerns. On the basis of the number of hours logged in service, the favorable inspection results, and the design margin, the Owners' Group expects that the AE piston skirts and rings would last the 40-year life of the plant. Non-nuclear users typically run engines 60,000 hours prior to replacing pistons and 20,000 hours prior to replacing rings.

The Owners' Group diesel management program will have requirements to monitor several parameters that would detect the need for an overhaul, or for intrusive inspections if problems develop. These parameters include engine compression, firing pressures, and crankcase pressure.

\section{cylinder Heads}

Cylinder heads for the DSR-48 series and DSRV-16 series engines are similar in design and are addressed as one component. Cylinder heads are grouped in three categories, Group I, II, or III. These groupings identify three distinct periods of design and design/fabrication control. These periods are marked by changes in the casting and fabrication of the heads and in the weld techniques used to repair the heads. Some of all three groups of heads remain in nuclear service today. PNL, in an earlier review, endorsed the Owners' Group findings and concluded that all groups of heads are adequate for their intended service (Reference 4, Section 4.10.3.3). Any cracks which develop would not be detrimental to engine performance. Water flow from a crack would be to the exterior of the engine, this flow would be readily detected and would allow the head to be repaired or replaced. As an added precaution against cylinder head cracking, air rolling of the engine with the indicator ports open is used at all sites to check for potential water leakage.

Cylinder head cracking or water inleakage has been observed. An earlier 10 CFR Part 21 notification regarding leakage through a small thinned area has been evaluated by the staff and a program to address the problem has been implemented. This is documented in the response to the notification. There are currentiy 304 heads in nuclear service on 20 engines.

This component has been extensively inspected. The average operating hours on the cylinder heads is 1,000 and some heads have operated for more than 2,000 hours. No cylinder head cracking has been identified, which has caused a loss of engine performance. On the basis of the large number of operating hours, and the favorable inspection results, the Owners' Group expects this component to last the 40-year plant life without needing overhaul. Non-nuclear users typically run their engines 35,000 hours before overhauling this type of component.

The Owners' Group diesel management program will require monitoring and trending of several parameters which would detect problems with this component and the need for further inspections. These include cylinder exhaust temperatures, compression, and firing pressures. In addition, a number of visual inspections and tests would be performed periodically to detect problems with this component. 


\section{Euel Injection Tubing}

A 10 CFR Part 21 notification was issued by the vendor on July 10, 1983, alerting TDI diesel engine owners and the NRC to a condition that may cause the tubing to fail. This condition results from a draw seam that acts as a stress riser on the inner surface of the tube. The draw seam is induced during the drawing phase of the manufacturing and generally will extend over most of the length of the tube and is readily detectable. $n$ in the basis of an analysis of the structural strength of the tubing, it was determined that the tubing is acceptable as long as no preexisting flaws greater than 0.0054-in. in depth existed. This prompted the recommendation to test the tubing for presence of cracks or to install shrouded tubing which has double walls. The reasons for the concern are the potential for fire resulting from a broken tube or a high-pressure fuel oil leak.

On the basis of the service record of this component and the ease of inspecting for leaks during operation, this component need not be overhauled. However, life of each fitting and tube assembly cannot be assured over the 40year life because of vibratory loads or wear and tear during maintenance. The Owners' Group is proposing periodic inspections to monitor tubing for leakage and repair as required. Commercial engine life for this component is approximately 35,000 hours.

\section{Push Rods}

Major problems with this component resulted from a previous TDI design which is no longer in use at nuclear facilities. Nuclear engines currently employ the friction-welded design. The performance of this design in nuclear service has been excellent. An Owners' Group evaluation indicates that there are acceptable factors of safety against failure due to fatigue or buckling for this component.

No problems have been identified since replacements were made with push rods incorporating the friction-welded design. On the basis of the design margins for this component, significant number of operating hours, and number of inspections, the Owners' Group expects this component to achieve the 40-year life without failure. Non-nuclear users typically run engines for 100,000 hours before replacing them. The Owners' Group diesel management program will require monitoring and trending of several parameters which would detect potential problems with this component and the need for further inspections.

\section{Rocker Arm Capscrews/Orive Studs}

During the initial DR/QR process, the Owners' Group determined that capscrew failures had occurred on an isolated basis. Fallures had been caused by insufficient preload on the capscrews. The Owners' Group performed a detailed design review of the component to ensure that the appropriate stresses are within allowable limits. The Owners' Group and PNL concluded in Reference 4, Section 4.18.4.3, that "If the rocker arm capscrews are installed with the proper preload, they should not require any $\mathrm{W} / \mathrm{S}$ until they are removed for other reasons." 
The Owners emphasized eliminating the cause of the original capscrew failures. Capscrew installation procedures have been modified to ensure proper preload, which was identified as a cause for the early failures. On the basis of the inspection results and the adequate design margins identified, the Owners' Group does not expect these components to need replacement during the 40-year life of the plant. These components are accessible with the subcovers removed and can be visually inspected. The Owners' Group diesel management program will have requirements for periodic inspections.

\section{Lower Liner Seals}

The lower liner seals consist of elastomeric 0 -rings that form a seal between the liner and block assembly. This seal prevents engine cooling water or jacket water from mixing with lube oil. The seals are made of Viton, an elastomer that has an excellent record of service in such applications. There are three seals for each cylinder which provide multiple barriers in the unlikely event that one of the seals fails.

Currently, these seals are replaced on a time-dependent basis. Monitoring the 0 il and jacket water levels gives an alternate means for determining if these seals need to be replaced. A significant number of inspections of these seals have revealed no degradation. In addition, the multiple seal design gives added protection against seal failure which could impact engine performance. On the basis of the failure monitoring capability, the multiple seal design feature and favorable inspection resuits, the Owners' Group does not expect the lower liner seals to need replacement during the 40-year life of the plant unless the liner is removed for other reasons. This conclusion is also supported by the vendor's non-nuclear engine experience. The Owners' Group diesel management program will have provisions for monitoring the condition of this component.

\section{Iurbochargers}

Problems associated with turbochargers have been related to bearing wear and damage to the stationary vanes due to vibration. To address bearing wear issues, the licensees have installed drip and full-flow prelubrication systems. These systems lubricate the turbocharger bearings during standby conditions prior to planned starts. In addition, the Owners' Group oil sampling program is a means of detecting metallic particles that would be an early indication of bearing wear. Finally, inspection results indicate (Table 1, Component MP-022/023, Reference 3) that significant bearing wear has not affected turbocharger performance.

Four TDI engines have experienced failure of a stationary vane at the turbocharger inlet. This condition was found on two of these engines as early as 1984 in the original DR/QR review. The Owners' Group, and its consultants, Failure Analysis Associates, determined the failures to be caused by highcycle fatigue. This fatigue results from the pulsations created by the engine exhaust during operation as the gases pass through the turbocharger inlet area to drive the rotating vane group. These failures, in all cases, resulted in the stationary vane being reduced to small pieces and passing through the rotating vanes of the turbocharger with no impact on the turbocharger or 
engine performance. Subsequent inspections following the loss of the stationary vanes revealed only small pits in the rotating vane group that required minor refurbishment and balancing. The Owners' Group discussed this with the NRC staff and its consultants in a meeting in January 1985 and concluded that no further action was required to qualify this component. This conclusion remains valid as subsequent inspections have revealed no information that would invalidate this conclusion.

The Owners' Group has determined that periodic overhauls of the turbocharger are required. The inspection of 38 turbochargers provides a well-documented basis for determining the appropriate overhaul frequency. These inspection results, coupled with an understanding of the impact of bearing wear on engine performance, installation of prelube systems to limit wear, and the availability of effective monitoring techniques will allow the TDI licensees to determine when turbocharger overhaul is required. In general, the data would indicate an overhaul frequency of once every five years. Similar data for non-nuclear engines show a need to overhaul turbochargers every 8,000 to 10,000 hours. The Owners' Group diesel management program will require monitoring and trending of parameters which would provide an early warning and need for an overhaul if problems develop. Cylinder exhaust temperatures would be monitored to assure that operation above the design temperature 1 imit of the component does not occur. Sustained operation above this limit could result in degraded performance. Vibration monitoring and variances in base line information would indicate an out-of-balance state resulting in premature bearing wear and other problems. Measurement and tracking of the thrust bearing wear will indicate remaining life of the bearing. 


\section{APPENDIX B \\ SUMAARY OF RECOMMENDATIONS BY THREE DIESEL GENERATOR EXPERTS}

Three recognized diesel experts, Messrs. Paul Louzecki, Adam Henriksen and B.J. Kirkwood participated in a review of the operational database and inspection results submitted by the Owners' Group. A summary of their recommendations and staffs evaluation of the recommendations are as follows:

Mr. Paul Louzecki offered these specific recommendations:

- Power output should be maintained at currently authorized loads for the River Bend station because of torsional vibration considerations and Grand Gulf because of connecting bolt size.

- TDI engines have experienced water pump problems due to torsional vibrations and wear. The Owners' Group should inspect/replace/refurbish these pumps on a schedule that will avoid failures. Design changes may also be considered.

- Connecting rod bolts on the 16 cylinder engines, should be checked for tightness every other refueling outage as part of the TDI Owners' Group program.

- $\quad$ Since TDI engines do not have many accumulated hours, even after 10 years in nuclear service, compared to more normal service engines, with correct monitoring and supporting program elements, it seems unnecessary to have mandatory overhauls at 10-year intervals.

The staff evaluated Mr. Louzecki's recommendations and determined that they have been factored in the Owners' Group diesel management program. The power outputs at the River Bend and Grand Gulf stations will continue to be maintained at the currently authorized loads.

Mr. Adam Henriksen offered a specific recomendation concerning the management of engines that exceed power ratings by more than insignificant time/power parameters or that operate at critical torsional conditions. He recommended a 750-hour operational run to verify absence of new fatigue sensitivity due to the abnormal operation. He also noted that as each unit completes 750 hours of operation, crankshaft and other fatigue-based inspections could be eliminated.

In addition, Mr. Henrikson offered the following:

- Deterioration of the 0-ring seals between the cylinder liner and the engine block is a special consideration in establishing the correct overhaul period. This deterioration is primarily a function of time and, to some degree, it may be affected by excessive piston impact. Puliing samples of liners to determine the 0-ring condition is the only means for monitoring its condition in considering an extension of the overhaul period. Within the current 10-year period, this seal is not 
expected to leak. In this application of static 0-ring service, considerable elasticity can be lost before leakage becomes a danger.

- Connecting rod bolts should be checked for tightness every five years as part of the TDI Owners' Group program.

- In addition to maintaining the surveillance requirements outlined in NUREG/CR-5057, cylinder compression, maximum pressures and cylinder leak-down testing (cold engine) should be checked during refueling outages.

The staff concurs with Mr. Henrikson's recommendations concerning the management of engines that exceed power ratings. The Owners' Group diesel management program will have comparable requirements to verify that abnormally-high torsional stresses have not been imposed. There are adequate provisions in the diesel management program to determine the condition of the o-ring seals and tightness of the connecting rod bolts. The other surveillance requirements recommended by $\mathrm{Mr}$. Henrikson will also be included in the diesel management program.

Mr. B. J. Kirkwood offered two specific recommendations:

- The 10-year inspection of nuclear service TDI engines is important. It seems necessary to have completed at least a few TDI engine overhauls after 10-year intervals to be able to judge the further adjustment to another time period.

- Turbochargers remain a concern. The risk of severe damage/failure is great from loose metalilic components being ingested into rotating turbo charger sections. Current preventive maintenance requirements relative to turbochargers are important and should be continued by the Owners' Group. It seems necessary to have completed at least a few TDI turbocharger overhauls after 5 and 10-year intervals, to be able to judge the adjustment in maintenance requirements and/or schedule.

The staff evaluated Mr. Kirkwood's recommendations and concluded that, the license conditions requiring 10-year teardown inspections are no longer necessary on the basis of: (1) a review of the operational database and inspection results of key EDG components; (2) high-median reliability of TDI diesels; (3) potentially-negative consequerices of intrusive inspections, and, (4) the Owners' Group's commitment to a comprehensive diesel management program developed in agreement with the engine manufacturer. The preventive maintenance requirements relative to turbochargers are included in the Owners' Group diesel management program. 
APPENDIX C

\section{IMPORTANT FEATURES OF A DIESEL GENERATOR PREVENTIVE MAINTENANCE PROGRAM}

In the development of the preventive maintenance program, a number of key features should be reviewed to provide assurance that the maintenance program will successfully achieve the reliability goals.

The first and most important feature that is necessary for a successful maintenance program is that the engineering conditions that are to be monitored as part of the program must be explicitly identified. Although the Owners' Group Program contains a good representative list of items to be monitored, each plant may wish to institute its own scheme, in order to treat the particular problems experienced by each licensee. Because there appear to be differences in the reliability problems experienced by different plants, even anong those using the same types of diesels, each plant must provide at least a nominal justification for the particular choice of a set of engineering conditions that it will monitor. It is not necessary for any plant to monitor all engineering conditions identified--only those important conditions that could prevent the emergency diesel generator (EDG) from achieving the reliability target.

Listed below are specific attributes that should be addressed by the diesel generator user:

- Monitoring of all key parameters such as temperatures (cooing water, lube oil, bearing, exhaust gases), pressures (cylinders, fuel, lube oil, air), speed, torque, load, or vibration levels.

- Establishing of sufficient test points for each parameter.

- Calibration and accuracy of monitoring equipment over time.

- Ensuring the rapid response of the monitoring equipment for adequate correlation of operating changes and parameter variations particularly under test conditions.

- Establishing the requisite frequency and accuracy of the data recorded.

- Ensuring the accurate recording (time, type, quantity) of all additions of fuel, lube oil, cooling water treatment chemicals, etc.

- Establishing the requisite frequency for sampling of all fluids (fuel, lube oil, cooling water).

- Ensuring that the fluid samples are representative (sampling point, volume, time at which the sample is taken in relation to other events) and that the analyses are properly specified. 
- Ensuring accurate recording (time, duration) of all operations of drains, blowdowns, and vents, along with the reasons for these operations.

- Ensuring that the engine data are being reviewed and analyzed on a regular basis and that remedial measures are taken, when necessary, in a timely manner.

The criteria for data analysis and corrective actions which include alert levels must be clearly identified for each of the engineering conditions contained in the set to be monitored as part of the EDG condition monitoring program. Alert levels are normally as simple as a minimum and/or maximum value for a parameter or a trend in a parameter. They also include combinations of condition levels (e.g., high crankcase pressure coupled with high temperature). A single engineering condition may have a multiplicity of alert levels, some of which merely alert the operator that a long-term phenomenon is continuing to progress at some rate toward eventual degradation. An example is the continuous change in acoustic vibration level at a given set of frequencies that may be tied to some wearout phenomena. The actuai "alert" may be a spectrum frequency level whereby the decision may be made, for the sake of prudence, to overhaul a portion of the EDG at the next scheduled reactor shutdown. Thus, the alert may require immediate action, or may simply result in a preventive maintenance action at some specified time in the future. Both the alert level value and a simple statement of the probable action to be taken should be presented as part of the condition monitoring plan.

The EDG condition monitoring program should be formalized in a set of procedures that contain checklists for the conditions monitored, monitoring frequencies, alert levels, and action statements for plant use. These checklists should contain the condition monitoring frequency, since there are separate checklists for checks per shift, per day, per week, etc. Alert levels and action statements would be condition specific and are highly dependent on the expected lag-time between observation of the engineering condition and the EDG failure mode related to the condition; severity of EDG failure mode related to the observed condition; and EDG repair outage time to correct the observed condition, compared to the repair outage time required if the condition were allowed to proceed to failure. These considerations should be implicit in the condition monitoring procedures.

As previously discussed, the frequencies with which the various EDG engineering conditions are to be sampled, or monitored, depend on the nature of the conditions and how they are related to the EDG failure mode that is being protected against. These frequencies must be set on the basis of the expected lag-time from observing the failure precursor condition to the subsequent failure mode; whether the observed condition is a direct observation of a condition that will eventually result in deteriorated reliability; and the severity of the failure if the failure mode were to occur. These considerations must be explicitly discussed in the condition monitoring frequency justification. 
It is generally beneficial from the standpoint of EDG availability to incur EDG outage time for the purpose of condition monitoring, which leads to preventive maintenance, in order to avoid the subsequent EDG failures that would be experienced had the preventive maintenance not been performed. However, it is still incumbent upon the licensee to ensure that EDG outages for condition monitoring and preventive maintenance do not become excessive. That is, the licensee's condition monitoring program must reflect the tradeoff of EDG reliability between preventive maintenance and EDG failure (and subsequent corrective maintenance).

It is inevitable that the appropriate set of monitored parameters and frequency of monitoring will change over time. This is true for two reasons: (1) because of wear and aging mechanisms, the important EDG fallure causes are expected to change with time and (2) additional failure information, and improved techniques for condition monitoring, will almost certainly result in a changed perception of the appropriate condition monitoring for an individual EDG. Therefore, it is important that the EDG maintenance program has provisions for periodically reviewing and updating the condition monitoring performed on the diesel generators. 


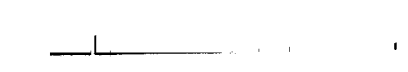




\section{APPENDIX D}

\section{SAMPLE LICENSE CONDITIONS}

The following is a sample of the license conditions that were imposed on TDI owner 1 icensees based on recommendations in NUREG-1216, in 1986, and their removal is being approved by the staff in this SE.

(1) General (applicable to all TDI engines)

Changes to the maintenance/surveillance program for the TDI diesel engines, as identified in [ ], shall be subject to the provisions of 10 CFR 50.59 .

The frequency of the major engine overhauls referred to in the 1 icense conditions below shall be consistent with Section IV.1, "Overhaul Frequency," in Revision 2 of Appendix II of the Design Review/Quality Revalidation Report that was transmitted by letter dated May 1, 1986, from J. B. George, Owners' Group, to H. R. Denton, NRC.

(2) Connecting Rods (applicable to TDI DSRV-16-4 and DSRV-20-4 engines only)

Connecting rods assemblies shall be subjected to the following inspections at each major engine overhaul:

- The surfaces of the rack teeth should be inspected for signs of fretting. If fretting has occurred, it should be subject to an engineering evaluation for appropriate corrective action.

- Ali connecting rod bolts should be lubricated in accordance with the engine manufacturer's instructions and torqued to the specifications of the manufacturer. The lengths of the two pairs of bolts above the crankpin should be measured ultrasonically before and after tensioning.

- The lengths of the two pairs of bolts above the crankpin should be measured ultrasonically before detensioning and disassembly of the bolts. If bolt tension is less than 93\% of the value at installation, the cause should be determined, appropriate corrective action should be taken, and the interval between checks of bolt tension should be reevaluated.

- All connecting rod bolts should be visually inspected for thread damage (e.g., galling), and the two pairs of connecting rod bolts above the crankpin should be inspected by magnetic particle testing to verify the continued absence of cracking. All washers used with the bolts should be examined visually for signs of galling or cracking, and replaced if damaged.

"Appropriate license conditions differ from plant to plant. 
- A visual inspection should be performed of all external surfaces of the link rod box to verify the absence of any signs of serviceinduced stress.

- All of the bolt holes in the link rod box should be inspected for thread damage (e.g., galling) or other signs of abnormalities. In addition, the boit holes subject to the highest stresses (1.e, the pair immediately above the crankpin) should be examined with an appropriate nondestructive method to verify the continued absence of cracking. Any indications should be recorded for engineering evaluation and appropriate corrective action.

The following item applies only to DSRV engines with connecting rods employing 1-7/8-in.-diameter bolts:

- The following actions should be performed if the engines are sperated in excess of $5740 \mathrm{~kW}$ :

(Specific actions have not yet been developed.)

(3) Crankshafts (applicable to TDI DSR-48 engines at Rancho Seco)

- During the first refueling outage, inspect the fillets and ofl holes of the three most heavily loaded crankpin journals (Nos. 5, 6, and 7) in each crankshaft, using 1iquid penetrant. Indications found should also be evaluated with eddy current methods as appropriate.

- During the second and third refueling outage, inspect the fillets and oil holes of the three most heavily loaded crankpin journals in each crankshaft, using 1 iquid penetrant. Indications found should also be evaluated with eddy current methods as appropriate.

- During each major engine overhaul, inspect the fillets and ofl holes of the (a) three most heavily loaded crankpin journals (Nos. 5, 6, and 7 ) and (b) the main journals located between crankpin journals 5,6 , and 7 .

- The following actions shall be performed if the engines are operated in excess of an indicated load of [31340 KW]:",

"Momentary transients (not exceeding $5 \mathrm{sec}$ ) that result from changing bus loads need not be considered as an overload.

"The figures shown in brackets are for River Bend, which has a qualified load capacity of $3130 \mathrm{Kw}$. For Rancho Seco, different values may be appropriate depending on the value of the qualified load established for the Rancho Seco TDI engine crankshafts. 
(a) For indicated engine loads in the range of [3130 Kw] to [ $3200 \mathrm{KW}$ ] for a period of less than 2 hours, no additional action shall be required.

(b) For indicated engine loads in the range of [3130 KW] to . [ $3200 \mathrm{KW}$ ] for a period of equal to or exceeding 2 hours," a crankshaft inspection pursuant to ttem d (below) shall be performed at the next refueling outage.

(c) For indicated engine loads in the range of [3200 kW] to [3500 kW] for a period of less than 1 hour, a crankshaftinspection pursuant to ttem $d$ (below) shall be performed for the affected engine at the next refueling outage.

(d) For indicated engine loads in the range of [3200 kW] fo [3500 kW] for a periods equal to or exceeding 1 hour, and for engine loads exceeding [ $3500 \mathrm{~kW}$ ] for any period of time, (1) the engine shall be removed from service as soon as safely possible, (ii) the engine shall be declared inoperable, and (iii) the crankshaft shall be inspected. The crankshaft inspection shall include crankpin journals 5, 6, and 7 (the most heavily loaded) and the two main journais in between, using 1 iquid penetrant. Indications found should be evaluated with eddy current testing as appropriate.

If cracks are found during inspections of crankshafts, this condition shall be reported promptly to the NRC staff and the affected engine shall be considered inoperable. The engine shall not be restored to "operable status" until the proposed disposition and/or corrective actions have been approved by the NRC staff.

(4) Crankshafts (appl fcable only to DSRV-20-4 crankshafts at San Onofre Unit 1)

- 011 hole locations in the five most heavily loaded main journals (i.e., Journals 8 through 12) for each crankshaft shall be inspected at each refueling outage with liquid penetrant. Indications found shall be evaluated with eddy current testing as appropriate.

- During each major engine overhaul, the fillets of the most heavily loaded main journals (Nos. 4 through 12) should be inspected together with the oil holes, using liquid penetrant. Indications found shall be evaluated with eddy current testing as appropriate. In addition, these inspections should be performed for the oil holes and fillets in at east three of the crankpin journals at each major engine overhaul.

"If there are multiple overload events within a given load range since the previous crankshaft inspection, then the time criterion applies to the total accumulated time in that load range. 
- The following actions shall be performed if the engines are operated in excess of $4500 \mathrm{~kW}(+5 \%)$ :

(NOTE: Specific actions applicable to San Onofre Unit 1 have not yet been developed. These actions should be specified in a manner similar to that used for River Bend.)

If cracks are found during inspections of crankshafts, this condition shall be reported promptly to the NRC staff and the affected engine shall be considered inoperable. The engine shall not be restored to "operable status" unt 11 the proposed disposition and/or corrective actions have been approved by the NRC staff.

\section{(5) Cylinder Blocks (applicable to all TDI engines)}

- Cylinder blocks shall be inspected for "ligament" cracks, "stud-tostud" cracks and "stud-to-end" cracks as defined in a report "by Failure Analysis Associates, Inc. (FaAA) entitled "Design Review of TDI R-4 and RV-4 Series Emergency Diesel Generator Cyl inder Blocks" (FaAA Report No. FaAA-84-9-11.1) and dated December 1984. (Note that the FaAA report specifies additional inspections to be performed for blocks with "known" or "assumed" ligament cracks.) The inspection intervals (1.e., frequency) shall not exceed the incervals calculated using the cumulative damage index model in the subject FaAA report. In addition, inspection methods shall be consistent with or equivalent to those identified in the subject FaAd report.

- In addition to inspections specified in the aforementioned FaAA report, blocks with "known" or "assumed" ligament cracks (as defined In the FaAA report) should be inspected at each refueling outage to determine whether or not cracks have initiated on the top surface, which was exposed because of the removal of two or more cylinder heads. This process should be repeated over several refueling outages unt 11 the entire block has been inspected. Liquid penetrant testing or a similar sensitive nondestructive testing technique should be used to detect cracking, and eddy current testing should be used as appropriate to determine the depth of any cracks discovered.

- If inspection reveals cracks in the cylinder blocks between stud holes of adjacent cylinders ("stud-to-stud" cracks) or "stud-to-end" cracks, this condition shall be reported promptly to the NRC staff and the affected engine shall be considered inoperable. The engine shall not be restored to "operable status" unt11 the proposed disposition and/or corrective actions have been approved by the NRC staff.

"This report was transmitted to H. R. Denton, NRC, from C. L. Ray, Jr., TDI Owners' Group, by letter dated December 11, 1984. 
The following air-roll test shall be performed as spectfied belowe except when the plant is already in an Action statement of Technical Spectfication 3/4.8.1. "Electric Power Systems. A.C. Sources":

The engine shall be rolled over with the airstart system and with the cylinder stopcocks open before each planned start, unless that start occurs within 4 hours of a shutdown. The engines shall also be rolled over with the airstart system and with the cylinder stopcocks open after 4 hours, but no more than 8 hours, after engine shutdown and then rolled over once again approximately 24 hours after each shutdown. (If an engine is removed from service for any reason other than the rollingover procedure before expiration of the 8-hour or 24-hour perlods noted above, that engine need not be rolled over while it is out of service. The licensee shall air-roll the engine over with the stopcocks open at the time it is returned to service.) The origin of any water detected in the cylinder must be determined, and any cylinder head that leaks because of a crack shall be replaced. The above air-roll test may be discontinued following the first refueling outage subject to the following conditions:

- All cylinder heads are Group III heads (1.e., cast after September 1980).

- Quality revalidation inspections, as identified in the Design Revtew/Quality Revalidation report, have been completed for all cylinder heads.

- Group III heads continue to demonstrate leak-free performance. This should be confirmed with TDI before air-roll tests are discontinued.

(7) Piston Skirts (applicable to modified type AF piston skirts only)

- The stud boss attachments of the modified type AF piston skirts shall be inspected with liquid penetrant at each major engine overhaul. Indications found should also be inspected with eddy current methods as approprlate. (This Iicense condition may be deleted for individual piston skirts after they have completed 750 hours of service at engine loads equaling $4500 \mathrm{~kW}(+5 \%))$ :

- The following actions shall be performed if the engines are operated in excess of $4500 \mathrm{kH}(+5 \%)$ :

(Specific actions have not yet been developed.)

(8) Iurbochargers (applicable to Elliot Model 656 and $90 G$ turbochargers of al1 TOI engines)

Periodic inspections of the turbochargers shall include the following: 
- The turbocharger thrust bearings should be visualiy inspected for excessive wear after 40 nonprelubed starts since the previous visual inspection.

- Turbocharger rotor axtal clearance should be measured at each refueling outage to verify compllance with TDI/EII fott

specifications. In addition, thrust bearing measurements should be compared with measurements taken previously to determine a need for further inspection or corrective action.

- Spectrographic and ferrographic engine ofl analysis shall be performed quarterly to provide early evidence of bearing degradation. Particular attention should be paid to copper level and particulate size, which could signify thrust bearing degradation.

- The nozzle ring components and inlet guide vanes should be visually inspected at each refueling outage for missing parts or parts showing distress on a one-turbocharger-per-refuel ing-outage basis. In addition, these inspections should be performed for ali turbochargers at each turbocharger overhaul (1.e., at approximately 5-year intervals). If any missing parts or distress is noted, the entire ring assembly should be replaced and the subject turbocharger should be reinspected at the next refueling outage. 


\section{APPENDIX E}

CONPONENTS REQUIRING ENGINE LOAD LIMITS AND/OR SPECIAL ROUTINE MAINTENANCE AND SURVEILLANCE

\begin{tabular}{|c|c|c|}
\hline Component & $\begin{array}{l}\text { Engine } \\
\text { load } \\
\text { limited }\end{array}$ & $\begin{array}{l}\text { Special } \\
\text { maintenance } \\
\text { and } \\
\text { survefllance } \\
\text { required }\end{array}$ \\
\hline $\begin{array}{l}\text { Crankshaft } \\
\text { DSR-48 } \\
\text { DSRV-48 }\end{array}$ & $\begin{array}{l}\text { Yes } \\
\text { Yes* }\end{array}$ & $\begin{array}{l}\text { Yes } \\
\text { Yes }\end{array}$ \\
\hline $\begin{array}{l}\text { Cyl Inder block } \\
\text { DSR-48 (Shoreham) } \\
\text { DSRV-16 (Comanche Peak) }\end{array}$ & $\begin{array}{l}\text { No } \\
\text { No }\end{array}$ & $\begin{array}{l}\text { Yes } \\
\text { Yes }\end{array}$ \\
\hline Cylinder heads & No & Yes \\
\hline $\begin{array}{l}\text { Connecting rods } \\
\text { DSRV engines, } 1-7 / 8-\text { in. bolts } \\
\text { DSRV engines, } 1-1 / 2-\text { in. boits } \\
\text { Piston skirts } \\
\text { Type AF }\end{array}$ & $\begin{array}{l}\text { Yes } \\
\text { No } \\
\text { Yes }\end{array}$ & $\begin{array}{l}\text { Yes } \\
\text { Yes } \\
\text { Yes }\end{array}$ \\
\hline Turbocharger & No & Yes \\
\hline
\end{tabular}



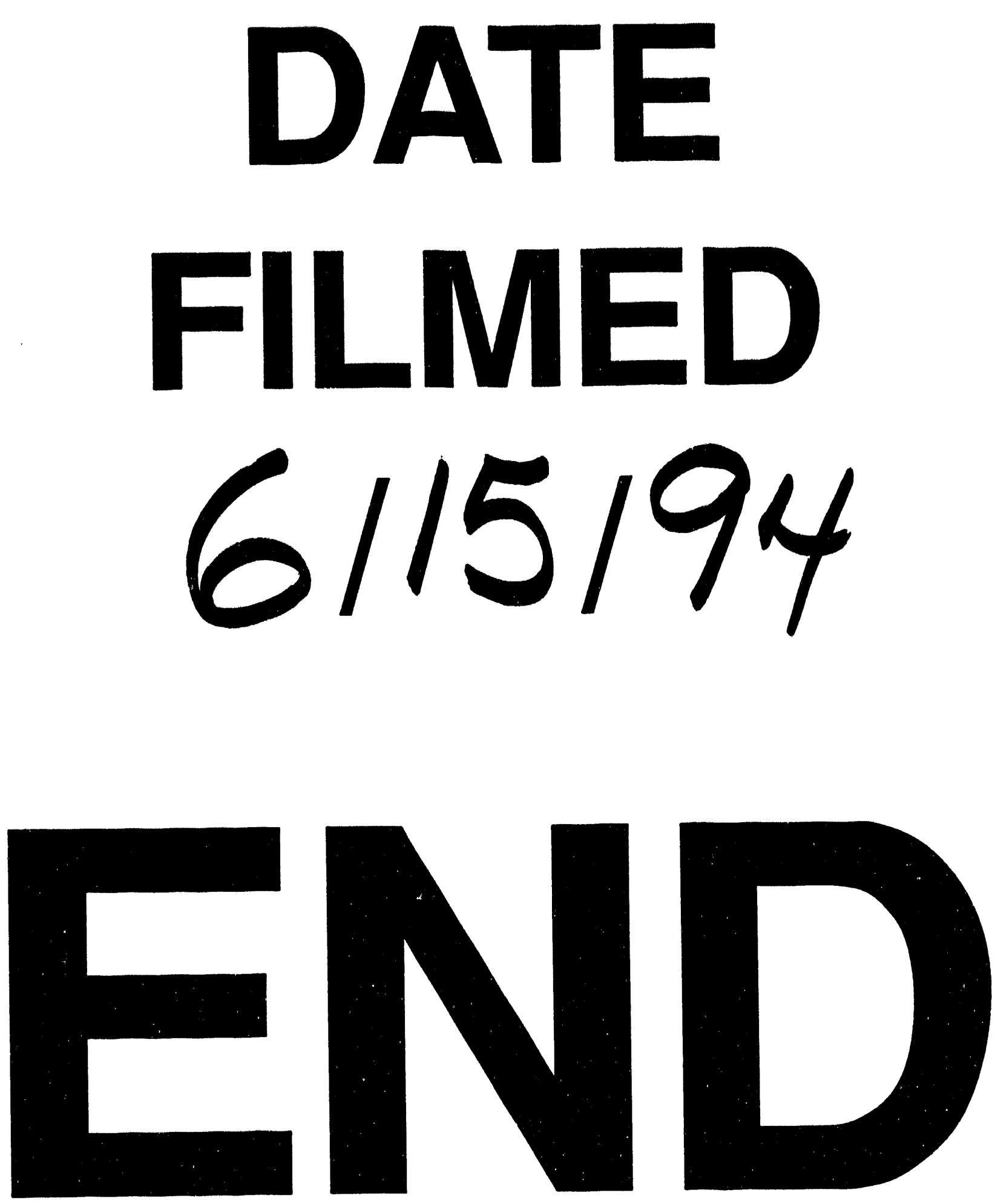
$$
2
$$

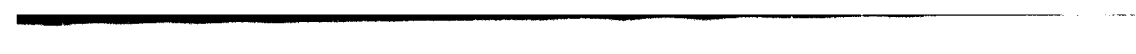

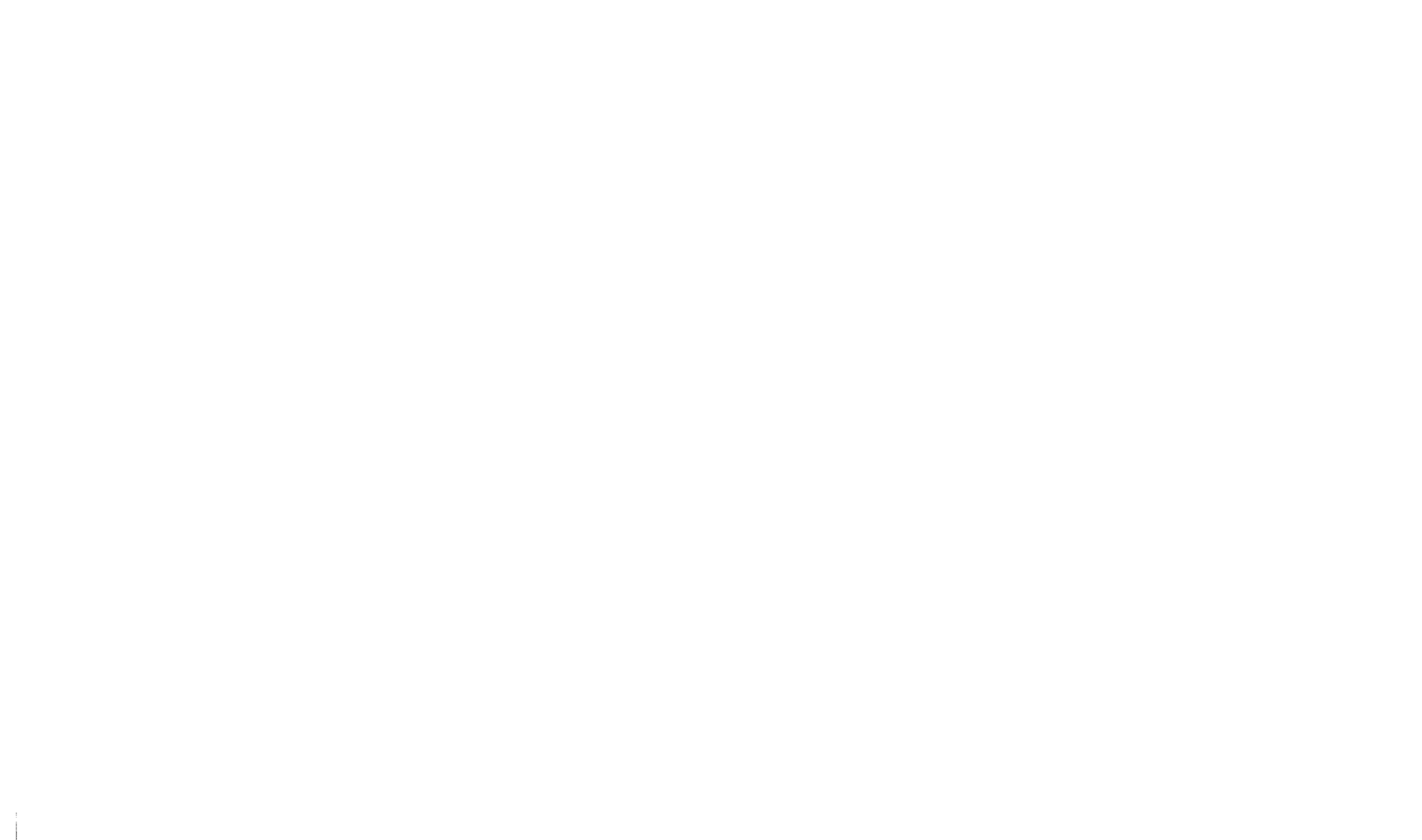

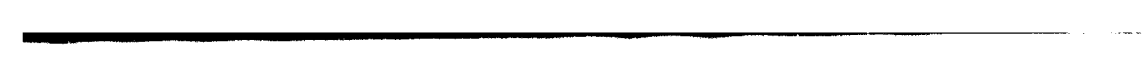

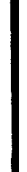

